\title{
Minimum RR Duration
}

National Cancer Institute

\section{Source}

National Cancer Institute. Minimum RR Duration. NCI Thesaurus. Code C62093.

The minimum duration (time) between successive peaks of $\mathrm{R}$ waves in a particular set of RR intervals. 